Check for updates

Cite this: RSC Adv., 2017, 7, 31745

Received 22nd March 2017

Accepted 9th June 2017

DOI: $10.1039 / c 7 r a 03358 c$

rsc.li/rsc-advances

\section{iTRAQ-based proteomic technology revealed protein perturbations in intestinal mucosa from manganese exposure in rat models}

\author{
Hui Wang, (D) *a Shengyi Wang, ${ }^{a}$ Dongan Cui, ${ }^{a}$ Shuwei Dong, ${ }^{a}$ Xin Tuo, ${ }^{a}$ Zhiqi Liu ${ }^{b}$ \\ and Yongming Liu*a
}

Manganese $(\mathrm{Mn})$ is an essential metal ion as a biological cofactor, but in excess, it is toxic; however, the homeostatic mechanisms of $\mathrm{Mn}$ at the cellular level have not been identified. We hypothesized that intracellular $\mathrm{Mn}$ can be modulated by proteins that could provide an insight into $\mathrm{Mn}$ regulatory mechanisms at the cellular level. Our experiment demonstrated that rats exposed to $M n\left(200 \mathrm{mg} \mathrm{L}^{-1}\right.$ in water for 5 weeks) showed a significant $\mathrm{Mn}$-induced decrease in total distance traveled, but daily body weight gain and feed intake were not significantly changed. The major organs showed a normal orientation and well defined histological structures without any signs of histopathological changes. We performed a qualitative and quantitative analysis of 3012 proteins for modifiers of cellular Mn content in intestinal mucosa cells by isobaric tags for relative and absolute quantitation (iTRAQ). Following stringent validation assays and bioinformatics, a total of 175 intestinal mucosa proteins were found that may regulate $\mathrm{Mn}$ levels under biologically relevant $\mathrm{Mn}$ exposures. These proteins are related to pancreatic secretion, protein digestion and absorption, fat digestion and absorption, biosynthesis of amino acids, glycerolipid metabolism, Alzheimer's and Parkinson's disease, mineral absorption associated protein, etc. The identified proteins and biological targets may have potential applications in vivo for modulating cellular Mn content, and will help us understand the homeostatic mechanisms of $\mathrm{Mn}$ at the cellular level.

\section{Introduction}

Metal ions have been demonstrated to play important roles in biological systems. These roles include the structural components of biomolecules, as signaling molecules, as catalytic cofactors in hydrolytic reactions and oxidation-reduction, and in the structural rearrangements of electron transfer chemistry and organic molecules. ${ }^{1}$ However, at high intracellular concentrations, metal ions are toxic because they can perturb cellular redox potential and produce highly reactive hydroxyl radicals. $^{2}$ The study of metal ion homeostasis and their importance for cell viability through protein-coding and regulatory machinery has been extensive. ${ }^{3,4} \mathrm{~A}$ battery of regulatory proteins in all cells mediate metal homeostasis by regulating the expression of genes that encode intracellular chelators, metal transporters or other detoxification enzymes. ${ }^{5}$ The homeostasis mechanisms of metal ions are maintained by

${ }^{a}$ Engineering and Technology Research Center of Traditional Chinese Veterinary Medicine of Gansu Province, Key Lab of New Animal Drug Project of Gansu Province, Key Lab of Veterinary Pharmaceutical Development of Ministry of Agriculture, Lanzhou Institute of Husbandry and Pharmaceutical Sciences of Chinese Academy of Agricultural Sciences, Lanzhou 730050, Gansu, China. E-mail: wanghui01@caas.cn; myslym@sina.com; Tel: +86-931-2115262

${ }^{b}$ Institute of Agro-Products Processing Science and Technology, Chinese Academy of Agricultural Sciences, Beijing 100193, China a concerted effect including metallochaperone proteins, metal transporters, transcription factors and metal responsive signaling pathways. ${ }^{6}$

Manganese (Mn) is an essential metal ion in some important physiological processes such as immune function, development, energy metabolism, reproduction, and antioxidant defenses. ${ }^{7}$ Incorporation of $\mathrm{Mn}$ into metalloproteins has beneficial effects, as these metalloproteins are involved with transferases, oxidoreductases, hydrolases, etc. ${ }^{8}$ But in excess, Mn brings neurotoxicity, and as a result, the body will experience a variety of psychiatric and motor disturbances due to basal ganglia dysfunction. ${ }^{9,10}$ In our previous publication, we found that $\mathrm{Mn}$-induced alterations are associated with metabolic responses to manganese poisoning, or manganism. Major alterations were observed in purine metabolism, amino acid metabolism and fatty acid metabolism. ${ }^{11}$ However, little is known about the complex regulatory biology involving the intracellular handling of Mn.

The critical function of the gastrointestinal tract is absorbing nutrients and water. ${ }^{12}$ Gastrointestinal changes could be detrimental to the performance, health and welfare of mammals. Mn uptake is regulated by the gastrointestinal tract by responding to dietary $\mathrm{Mn}$ levels; however, the molecular mechanisms are not fully understood. The action of the transporters involved in regulating uptake and efflux of Mn into cells 
is not well established and signaling pathways responsive to physiological Mn concentrations have not been described. ${ }^{13}$

Proteomics is a mechanism-based high throughput screening approach used to identify proteins expressed that may lead to pathology or disease outcomes in tissue types or certain cells at a given moment. ${ }^{14}$ Isobaric tags for relative and absolute quantitation (iTRAQ) is an isotope labeling technique, characterized by high throughput, high sensitivity and high accuracy-based proteomic technology. ${ }^{15}$ iTRAQ coupled with liquid chromatography-tandem mass spectrometry (LC-MS) can produce a full set of information through simultaneously isolating and identifying hundreds of proteins. ${ }^{16,17}$ Proteomics technologies have the potential ability to solve ecotoxicological issues and elucidate the underlying molecular mechanisms through screening critical proteins based on the protein expression signature (PES). ${ }^{\mathbf{1 8 , 1 9}}$ The PES is defined as the expression signature or expression pattern of a set of proteins as biomarkers. $^{20}$ Mn-specific signaling pathways or binding proteins responsive to physiological Mn concentrations in vivo have not been systematically described. To identify the differentially expressed proteins that modify cellular Mn content, the proteomics of iTRAQ was performed to identify the modifiers of intracellular and cellular regulation of $\mathrm{Mn}$ homeostasis and trafficking. Understanding the targets of PES could provide an insight into the regulatory mechanisms of $\mathrm{Mn}$ at the cellular level.

\section{Materials and methods}

\subsection{Ethics statement}

All experiments were carried out with respect and humanely for alleviation of suffering following the protocols approved by the Institutional Animal Care and Use Committee of Lanzhou Institute of Husbandry and Pharmaceutics Sciences of the Chinese Academy of Agricultural Sciences (animal use permit: SCXK20008-0013). We received approval for the specific procedures used in this study. Animals were maintained and experiments were conducted following the recommendations in the Guide for the Use and Care of Laboratory Animals. The weight, health status and body temperature of the rats were monitored on a daily basis. They were anesthetized using sodium pentobarbital (50 $\mathrm{mg} \mathrm{kg}^{-1}$ ) by intraperitoneal injection at the end point of the study, and then mounted in a stereotaxic device with heads held in a horizontal plane. All efforts were made to minimize suffering using analgesia, anesthesia, and post-injury care and monitoring. We confirm that the rats did not sustain any injury in our study.

\subsection{Animals and experimental design}

The experiment was performed on male Sprague-Dawley rats. Sixteen rats $(148 \pm 2 \mathrm{~g})$ were randomly allocated to either the control or Mn-treated group (eight rats per treatment group) and were housed in plastic cages ( 5 days adaptation and 5 weeks of feeding with experimental diets). All of the rats were housed under pathogen-free conditions on a $12 \mathrm{~h}$ light-dark cycle at 20 $\pm 3{ }^{\circ} \mathrm{C}$ and $40-60 \%$ relative humidity. During the first 5 days, all groups were fed the basal diet (AIN-93G). This was prepared according to guidelines described elsewhere $(35,10$, and $6 \mathrm{mg}$ $\mathrm{kg}^{-1}$ of $\mathrm{Fe}, \mathrm{Mn}$, and $\mathrm{Cu}$, respectively). ${ }^{21}$ The rats in the control group received the AIN-93G diet and non-ionic water, and those in the Mn-treated group were fed the AIN-93G diet and Mn-rich water (200 $\mathrm{mg} \mathrm{L}^{-1}$ ) for 5 weeks. According to WHO guidelines, the risk concentration for $\mathrm{Mn}$ in drinking water is $0.5 \mathrm{mg} \mathrm{L}^{-1} .^{22}$ All animals had free access to their diets and water. The body weight (BW) of all rats in each group was measured weekly.

\subsection{Behavior analysis}

An open-field measurement system was used to measure rats' activity at the end of the experiment; this system can automatically record all activities of the animal. Rats were transported (within their home cage) to acclimatize to the testing room for 1 hour before testing started. Control and Mn-treated rats were put in the separated testing open field chamber $(60 \mathrm{~cm} \times 60 \mathrm{~cm}$ $\times 60 \mathrm{~cm}$ ), and $6 \mathrm{~min}$ locomotor activity was automatically recorded by video surveillance. Cameras were mounted on tripods and placed parallel to the shoebox cages. The experiments were repeated three times in a 1 hour period. End points for analysis were the total distance travelled.

\subsection{Tissue collection}

At the end point of the study, rats were anesthetized using sodium pentobarbital. The small intestines were obtained immediately and thoroughly rinsed using normal saline then cut into $1 \mathrm{~cm}$ length segments and fixed in 10\% neutral formalin used for morphological analysis. Mucosa was obtained from the remaining segment as described previously and snap frozen using liquid nitrogen then stored at $-80{ }^{\circ} \mathrm{C}$ until biochemical and molecular analyses. ${ }^{23}$

The intestines, lung, spleen, kidney and testicles were harvested and rinsed using normal saline, then immersed immediately in $10 \%$ neutral buffered formalin for $24 \mathrm{~h}$. A gradient of alcohols was used for dehydration, and then the tissues were embedded in paraffin using conventional methods. ${ }^{\mathbf{1 1 , 2 4}}$ The tissues were sectioned into $4 \mu \mathrm{m}$ thick slices; slices were collected and mounted on microscope slides. For observation of morphological changes, hematoxylin-eosin staining was performed and a light microscope (Olympus x51 model, Tokyo, Japan) equipped with a camera (Olympus 20, Tokyo, Japan) was used.

\subsection{Intestinal mucosa protein extraction}

Total intestinal mucosa proteins were extracted according to Wang et al. ${ }^{23}$ with slight modifications. In brief, small samples of mucosal scrapings from the intestine were crushed using a mortar with liquid nitrogen. Approximately $100 \mathrm{mg}$ of each powdered sample was transferred to sterile tubes with $600 \mu \mathrm{L}$ of lysis buffer (SDT; containing 4\% SDS (w/v), $100 \mathrm{mM}$ Tris-HCl pH 7.6, 0.1 M DTT).

Each mixture was then sonicated in a boiling water bath using an ultrasonicator (Sonics \& Materials, Newtown, CT, USA) with $100 \mathrm{~W}$ power output. They were sonicated 10 times with $10 \mathrm{~s}$ on and $15 \mathrm{~s}$ off cycles. After that, each lysed cell suspension 
was sonicated in a boiling water bath for $15 \mathrm{~min}$ to solubilize the proteins, then the suspension was centrifuged at $13400 \mathrm{rpm}$ for $25 \mathrm{~min}$. The supernatant protein was collected and the protein concentration measured using the BCA (bicinchoninic acid) protein assay. The protein concentration was $23.64 \pm 4.07 \mu \mathrm{g} \mu \mathrm{L}^{-1}$.

\subsection{Protein digestion and peptide quantitation}

First, DTT was added to $40 \mu \mathrm{L}$ of protein from each sample (until the DTT concentration was $100 \mathrm{mM}$ ) in a boiling water bath for $5 \mathrm{~min}$, then it was cooled to room temperature. Next, $200 \mu \mathrm{L}$ of UA buffer (150 mM Tris- $\mathrm{HCl} \mathrm{pH} \mathrm{8.0,8} \mathrm{M} \mathrm{urea)} \mathrm{was}$ used to remove the DTT and detergent components by ultrafiltration (Microcon $10 \mathrm{kDa}$ centrifugal filter units), followed by centrifugation at $14000 \mathrm{~g}$ for $15 \mathrm{~min}$. Subsequently, $100 \mu \mathrm{L}$ of $0.05 \mathrm{M}$ iodoacetamide (IAA) in UA buffer was added to the concentrate followed by centrifugation at $14000 \mathrm{~g}$ for $10 \mathrm{~min}$. Then $100 \mu \mathrm{L}$ UA buffer was added to the resulting concentrate with centrifugation at $14000 \mathrm{~g}$ for $10 \mathrm{~min}$ and repeating this step a further two times. Afterwards, $100 \mu \mathrm{L}$ of Dissolution buffer was added, followed centrifugation at $14000 \mathrm{~g}$ for $10 \mathrm{~min}$, and this step was repeated two times. Finally, the protein suspensions were digested overnight at $37^{\circ} \mathrm{C}$ with $40 \mu \mathrm{L}$ trypsin buffer ( $3 \mu \mathrm{g}$ trypsin in $40 \mu \mathrm{L}$ dissolution buffer). The peptides were quantified using UV light at $280 \mathrm{~nm} .^{25}$

\section{7 iTRAQ labeling}

The iTRAQ Reagent 8-plex Multiplex Kit (Applied Biosystems, Foster City, CA, USA) was used to label each sample according to the manufacturer's instructions. The controls of normal small intestine tissue samples were labeled as (Sample 1)-113, (Sample 2)-114, (Sample 3)-115 and (Sample 4)-116, while Mntreated samples were labeled as (Sample 5)-117, (Sample 6)118, (Sample 7)-119 and (Sample 8)-121.

\subsection{Peptide fractionation and LC-MS/MS analysis}

Strong cation exchange (SCX) chromatography was used to fractionate iTRAQ labeled mixed peptides on a 20AD HPLC system (Shimadzu; Kyoto, Japan) using a polysulfoethyl column (5 $\mu \mathrm{m}, 200 \AA$, $2.1 \times 100 \mathrm{~mm}$, The Nest Group, MA, USA).

Then the samples were analyzed by $\mathrm{Q}$ Exactive mass spectrometer (Thermo Finnigan). The samples were added to a C18reversed phase column in buffer A, then separated with buffer

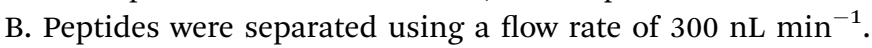
The gradient profile was: $0-50 \% \mathrm{~B}$ in $0 \mathrm{~min}$ to $220 \mathrm{~min}, 50-$ $100 \%$ B in $220 \mathrm{~min}$ to $228 \mathrm{~min}$ and $100 \%$ B in 228 to $240 \mathrm{~min}$.

Tandem mass spectrometry was used to identify the different components on the top 15 ions. Full MS scans were applied at 70k resolution with a $3 \mathrm{e} 6$ AGC target and a scan range of 300$1800 \mathrm{~m} / \mathrm{z}$. The 10 fragment patterns were collected after each full scan. MS2 scans were monitored with a $2.0 \mathrm{~m} / \mathrm{z}$ isolation window, $17.5 \mathrm{k}$ resolution with a 1e5 AGC target, $60 \mathrm{~ms}$ maximum injection time, and a normalized collisional energy (NCE) of $30 \mathrm{eV}$.

\subsection{Data analysis}

MS/MS spectra were embedded in the software of Proteome Discoverer 1.4 (thermo) against the uniprot_rat_33675_ 20141101.fasta (33 675 sequences, downloaded on 11 November 2014) and decoy databases and analyzed using Mascot 2.2 (Matrix Science). The following options were used for protein identification: peptide mass tolerance $=20 \mathrm{ppm}$, enzyme $=$ trypsin, missed cleavage $=2$, and fragment MS/MS tolerance $=0.1 \mathrm{Da}$; carbamidomethyl $(\mathrm{C})$, iTRAQ8plex $(\mathrm{K})$ and iTRAQ8plex (N-term) were set as fixed modifications; oxidation $(\mathrm{M})$, iTRAQ8plex $(\mathrm{Y})$, and false discovery rate $(\mathrm{FDR}) \leq 0.01$ were set as variable modifications. ${ }^{26}$ The peak intensity was extracted using Proteome Discoverer 1.4 from each fragmentation spectrum.

The peptides identified that expressed changes in comparison with the control were calculated based on the ITRAQ reporter ion intensities. Twofold changed cut-offs were selected as significantly changed to categorize proteins based on statistical analysis and relative quantification, that is, the proteins were considered to be up-regulated if iTRAQ ratios $>1.2$, whereas they were considered to be down-regulated if iTRAQ ratios $<0.83$.

\subsection{Bioinformatics}

Proteins were further analyzed for biological and functional relevance based on statistically significant differences. These proteins were classified using their gene function and the freely available Gene Ontology (GO) by biological pathways. NCBI BLAST+ client software was used to identify homologous proteins based on the functional annotation to transfer to the targeted proteins. The top 10 blast hits for each query protein with an $E$-value less than $1 \times 10^{-3}$ were retrieved and loaded into Blast2GO (Version 2.7.2) for GO pathway annotation and mapping using the Kyoto Encyclopedia of Genes and Genomes (KEGG) Automatic Annotation Server (http://www.genome.jp/ tools/kaas/). In addition, a functional and differentially expressed protein association network was built using Search Tool of the Retrieval of Interacting Genes/Proteins (STRING; http://string.embl.de/).

\subsection{Statistical analysis}

Statistical analyses were conducted using SPSS version 19.0 software (SPSS, Inc., Chicago, IL, USA) and a difference at $P<$ 0.05 was considered to be statistically significant. Data were expressed as mean \pm S.D.

\section{Results and discussion}

\subsection{Mn exposure significantly decreased locomotion}

The open field test is a widely used procedure for examining the behavioral effects of drugs. ${ }^{27}$ Because altered locomotion is associated with Mn exposure, we conducted behavioral analysis during the fifth week of Mn exposure using video surveillance to monitor Mn-induced changes in activity. Depicting behaviors revealed a significant $\mathrm{Mn}$-induced decrease in total activity in the Mn-exposed group $(P<0.01)$, measured as total distance 
traveled at the end of the experiment (Fig. 1). Excess Mn in the brain is neurotoxic and known as manganism. ${ }^{28}$ Previous studies have reported that excess $\mathrm{Mn}$ will produce a variety of psychiatric and motor disturbances including decreased motor skills, memory deficits and psychotic behavior resembling Parkinson's disease due to basal ganglia dysfunction.9,10,28 The results indicated that a model of $\mathrm{Mn}$ poisoning was established and the behavioral patterns displayed significant changes in the body produced by motor disturbances due to excess Mn which could lead to the accumulation of neurofibrillary tangles (striatum, globus pallidus and substantia nigra), ${ }^{29}$ a hallmark of Parkinson's disease.

\subsection{Effect of manganese exposures on body weight of rats}

Body weights (BW) of rats during each week of the experiment are shown in Fig. 2. The BW increased gradually, but the doses and period of Mn exposures had no significant effect on the BW of Mn-treated rats compared with the control group in this study $(P>0.05)$. Our experiment demonstrated that longer Mn exposure time influenced the behavioral pattern of animals, but feed intake and daily BW gain were not significantly different.

\subsection{Effect of manganese exposure on histopathology}

The histopathology of the major organs was studied. No histopathological changes were observed in the intestine, lung, spleen, kidney and testicle of the rats after exposure to Mn at $200 \mathrm{mg} \mathrm{L}^{-1}$ for 5 weeks (Fig. 3). The small intestine of mammalians provides an extensive contact surface for ingested compounds. Absorption and metabolism of xenobiotics, nutrients and drugs are enabled by the unique morphological and functional properties of the small intestine. ${ }^{30}$ Horning et al. reported that the nervous system is the primary target for excessive $\mathrm{Mn}$, and that $\mathrm{Mn}$ exposure has not been linked with damage to the kidney, liver, skin, blood, or stomach. ${ }^{7}$ But in our previous study, we found extensive necrosis and dissolved
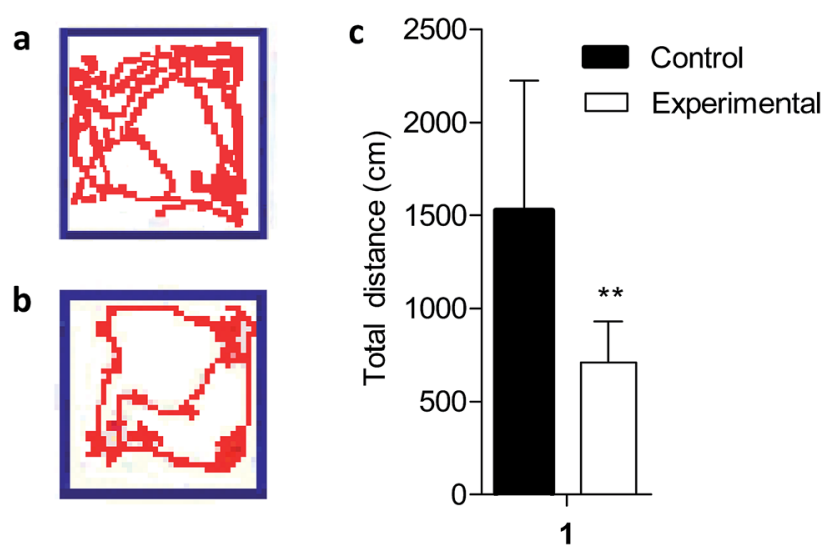

Fig. 1 Decreased locomotor behavior in Mn-treated rats. An openfield test was performed to test the locomotor activity of the $\mathrm{Mn}$ treated rats. Motion trails of (a) controls and (b) Mn-treated rats, and distance traveled (c) were recorded in the open-field test. It showed a significant decrease in locomotor behavior in the $\mathrm{Mn}$-treated rats. $* * P<0.01$.

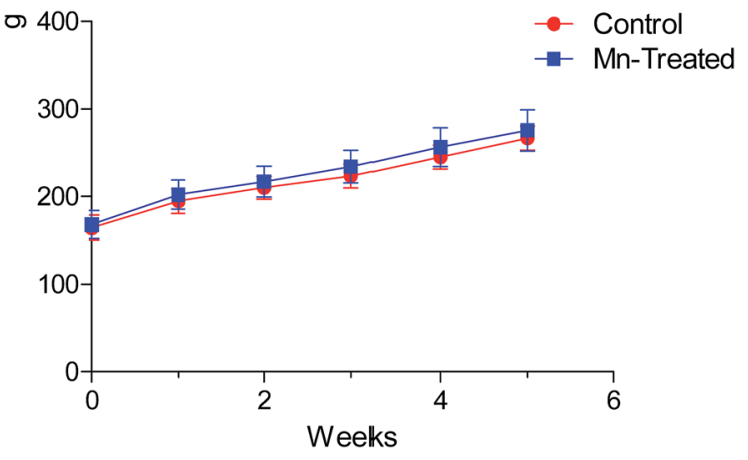

Fig. 2 Body weight of rats during the experimental period. No statistically significant difference was observed in the body weight of rats between $\mathrm{Mn}$ treated and control groups $(P>0.05)$.

nuclei in hepatic tissue in the Mn-treated group of rats. ${ }^{\mathbf{1 1}}$ The reason for this phenomenon is because the liver plays a major role in Mn excretion, and impairment of liver function results in excessive retention of $\mathrm{Mn}^{31}$ Our results indicated that $\mathrm{Mn}$ exposure did not damage every organ in the body.

\subsection{Proteomic alterations of small intestine in response to Mn-treated}

The homeostasis of transition metal ions in all cells are mediated by a list of regulatory proteins through modulating the expression of genes that encode intracellular chelators, metal transporters and/or other detoxification enzymes. ${ }^{5}$ Small intestinal enterocytes contain a large variety of regulatory proteins, plasma membrane transporters, intracellular binding proteins, metabolic enzymes, and others within the basolateral membrane. ${ }^{\mathbf{3 0 , 3 2}}$ The enterocytes have a rapid turnover, which allows quick cellular adaptation and quick replacement of cells in response to diets or exposure to xenobiotics. ${ }^{30}$ The advantages of proteomics technology are high throughput, high sensitivity, rapid testing of small molecules, and discovery of new proteins that are related to disease. ${ }^{33}$ iTRAQ along with LCMS is a robust protein discovery technique, allowing the determination of which proteins are affected in intestinal mucosa cells under biologically relevant Mn exposures. Our application of iTRAQ-based proteomic technology targeted specific enzymatic or protein processes with rapid testing of small molecules. This approach would be expected to lead to many potential protein or biological targets.

In the current study, rats were treated with Mn for 5 weeks, and at the end of the experiment, the small intestine mucosa were collected and used for protein extraction, protein digestion and iTRAQ labeling to provide more information about proteomes on exposure to $\mathrm{Mn}$. A total of 3012 proteins in intestinal mucosa cells were quantitatively and qualitatively analysed by iTRAQ in this study. The statistically significant proteins were detected using the ANOVA test $(P<0.05)$, and if the iTRAQ ratio was less than 1.2, the proteins were discarded. A total of 175 intestinal mucosa proteins passed the criteria, and may modulate intracellular Mn levels based on their statistically significant abundance $(P<0.05)$ (Table 1$)$. Table 1 shows that 

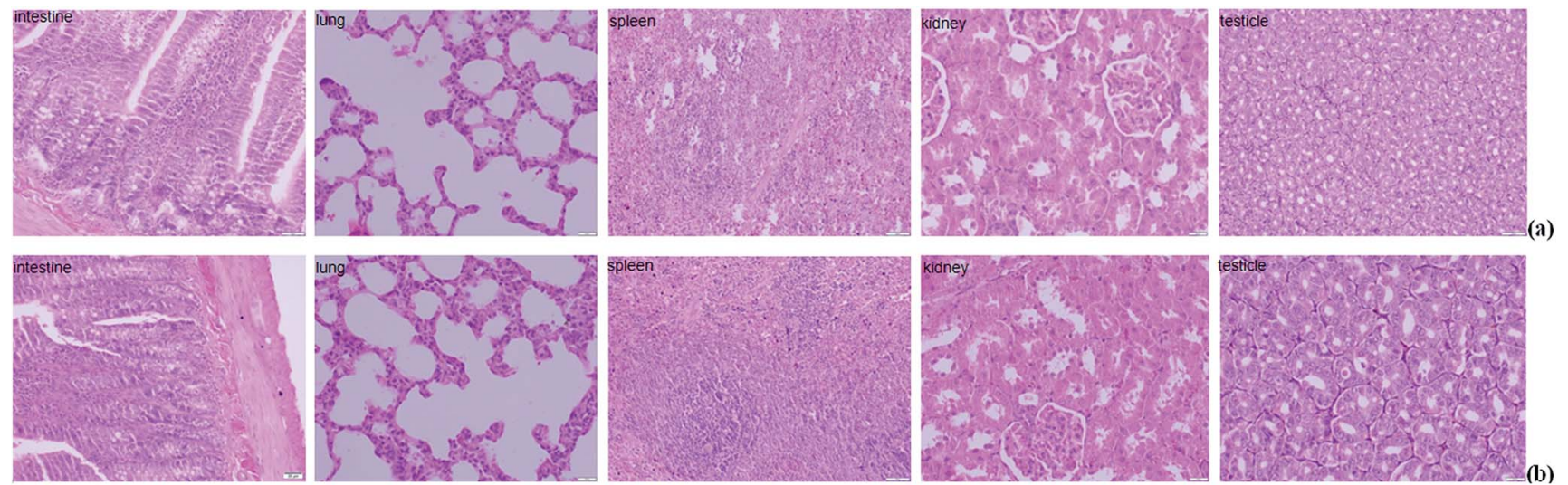

Fig. 3 Hematoxylin and eosin staining of the tissue sections collected from the different groups ((a) control and (b) Mn-treated) of rats after the experiment. The major organs showed normal orientation and well-defined histological structures without any signs of histopathological changes.

the expression of 108 different proteins in rat small intestinal mucosa were down-regulated, whereas 67 were up-regulated. The 175 proteins were assigned to seven functional groups, i.e. metabolism (amino acid, lipid and sugar metabolism), binding proteins, disease (Alzheimer's disease, Parkinson's disease, amyotrophic lateral sclerosis, etc.), cellular component and process, oxidative stress, signaling pathway, and enzymatic activity based on Gene Ontology (GO) classification (Table 1). This small group of proteins will help us understand the homeostatic processes mediating normal cellular Mn content.

Among these proteins, fatty acid-binding protein (P02692) was down-regulated after $\mathrm{Mn}$ exposure. Fatty acid-binding protein is an important cytosolic protein in small intestine epithelial cells, and participates in the uptake, intracellular metabolism and transport of long chain fatty acids. ${ }^{34}$ The downregulation of fatty acid-binding protein in our study suggested that $\mathrm{Mn}$ exposure might have interrupted the lipid metabolism and fatty acid transport of the intestine. Apart from this protein, chymotrypsin (P00774, F1MA56, P00773 and G3V8J3) and trypsin (G3V7Q8, P00762 and P00763), two important proteolytic enzymes involved in the digestive systems of mammals, ${ }^{35}$ were significantly down-regulated after Mn exposure. Hence, we speculated that a high concentration of Mn ion might destroy the absorptive functions of the intestinal epithelium through inhibiting the activities of digestive enzymes.

The oxidation states of $\mathrm{Mn}^{2+}$ and $\mathrm{Mn}^{3+}$ are the two common species in the human body and can cycle through redox. ${ }^{36}$ The Mn redox cycle provides a 'double-sword' effect on nutritional metabolism and toxic effects on biological function. Mn serves as a cofactor for Mn superoxide dismutase (MnSOD) that catalyzes superoxide $\left(\mathrm{O}_{2}{ }^{--}\right)$to hydrogen peroxide $\left(\mathrm{H}_{2} \mathrm{O}_{2}\right)$ and thereby detoxifies free radicals in the mitochondria to prevent oxidative stress through the $\mathrm{Mn}^{2+} / \mathrm{Mn}^{3+}$ cycle. ${ }^{28}$ But the $\mathrm{Mn}^{2+} /$ $\mathrm{Mn}^{3+}$ cycle can also accelerate dopamine auto-oxidation to form cytotoxic quinones and produce reactive oxygen species (ROS). ${ }^{37}$ Oxidative stress and dysregulation of neurological signaling seem to be the mechanisms involved in the neurodegeneration caused by Mn, and they have been found as a consequence of
Mn toxicity in the brain. ${ }^{38-40}$ Our proteomic analysis found that 10 proteins related to oxidative stress were down-regulated significantly in Mn-treated rats. Peroxiredoxin (Q9Z0V5) is a highly expressed antioxidant enzyme that catalyzes and scavenges hydrogen peroxide and other ROS. ${ }^{35}$ The present study also demonstrated that $\mathrm{Mn}$ exposure decreases the activities of $17 \beta$-hydroxysteroid dehydrogenase (Q5M875). Interactions between the antioxidant and steroidogenic enzyme systems are physiologically relevant. ${ }^{41}$ The data on antioxidant status in $\mathrm{Mn}$ treated rats obtained in the present study are in agreement with the observed changes in the activities of steroidogenic enzymes indicating an imbalance in pro-oxidant and antioxidant systems, leading to oxidative stress in manganese-exposed rats. Heat shock proteins are highly regulated proteins that are involved in normal cellular activity, but when the cell is exposed to heat or excess ROS production, they will be up-regulated. ${ }^{35,42}$ Our results found that the level of heat shock protein (G3V913) increased after $\mathrm{Mn}$ exposure. This result indicated that $\mathrm{Mn}$ exposure might induce excess ROS production in the intestine, which enhances the expression of heat shock protein and depresses the expression of antioxidative enzymes, and subsequently destroys the antioxidant defense barrier of the intestines.

The altered expression of components of protein complexes that are involved in RNA processing and protein translation was also observed in our study. Although changed protein concentrations cannot be directly correlated with changed functions, the resulting changes strongly indicate altered digestion, absorption, and metabolism as well as oxidative stress within the small intestine.

\subsection{Gene Ontology annotation}

Gene Ontology (GO) functional annotation and enrichment analysis are useful for the analysis of large genomic and proteomic datasets. ${ }^{43}$ The biological events behind the data can be speculated through examining significantly overrepresented GO terms and provide a primary overview of the intestinal mucosa proteome. Blast2GO (Version 2.8.0) uses 
Table 1 The list of differentially expressed proteins in intestinal mucosa cells in rats induced by Mn exposure by iTRAQ identification

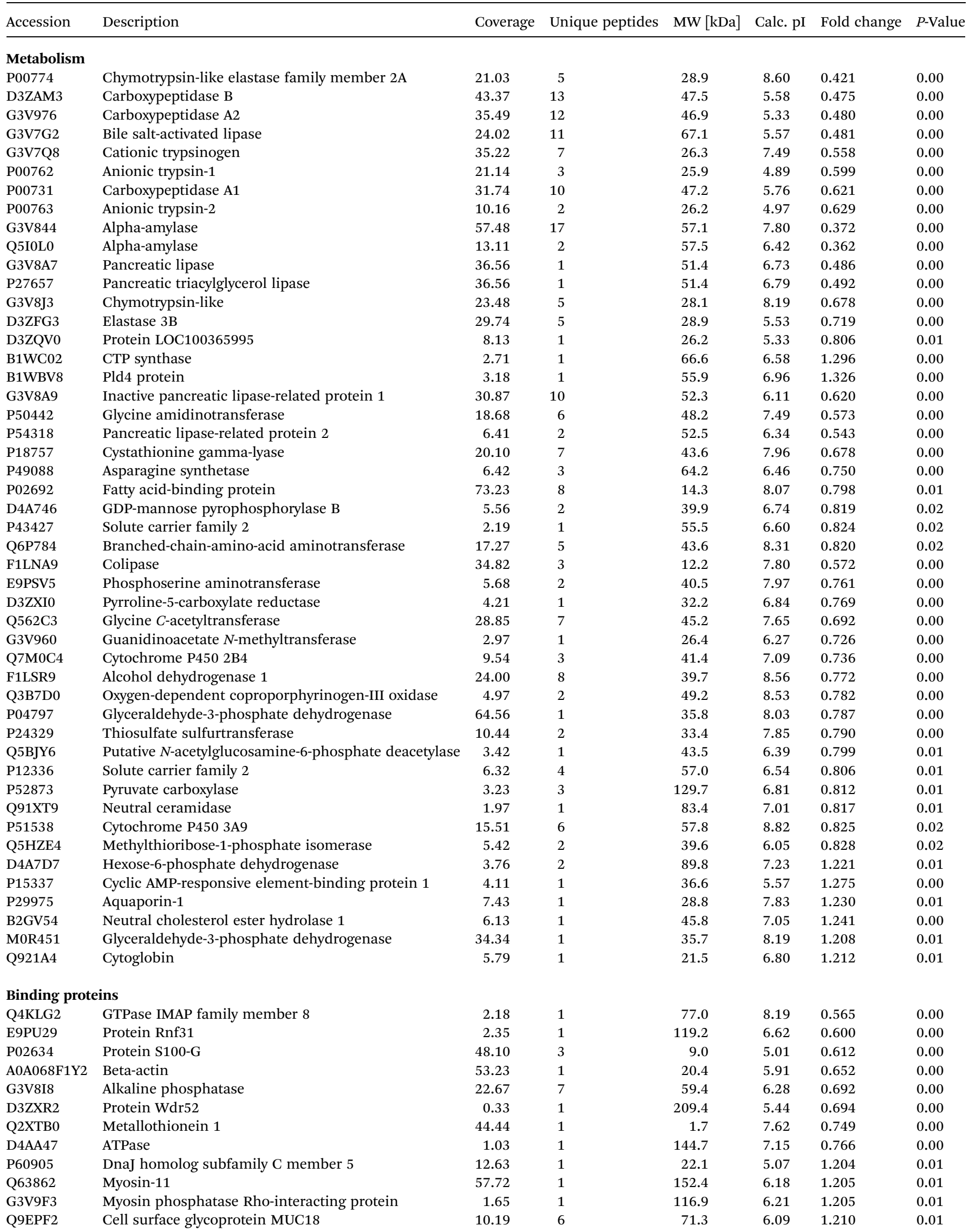


Table 1 (Contd.)

\begin{tabular}{|c|c|c|c|c|c|c|c|}
\hline Accession & Description & Coverage & Unique peptides & MW [kDa] & Calc. pI & Fold change & $P$-Value \\
\hline G3V9E3 & Caldesmon 1 & 39.17 & 20 & 60.6 & 6.58 & 1.210 & 0.01 \\
\hline Q99N97 & H-Caldesmon & 27.75 & 6 & 26.6 & 4.98 & 1.212 & 0.01 \\
\hline F1M265 & Palladin & 22.63 & 12 & 79.0 & 7.17 & 1.220 & 0.01 \\
\hline Q62896 & BET1 homolog & 15.25 & 1 & 13.2 & 9.07 & 0.798 & 0.01 \\
\hline F1LP76 & Elongator complex protein 1 & 0.83 & 1 & 149.1 & 6.34 & 0.801 & 0.01 \\
\hline Q9QYF3 & Unconventional myosin-Va & 0.66 & 1 & 211.6 & 8.69 & 0.805 & 0.01 \\
\hline G3V8M5 & Serine/threonine-protein phosphatase & 8.79 & 1 & 35.1 & 5.06 & 0.808 & 0.01 \\
\hline F1MAD9 & Structural maintenance of chromosomes protein & 1.01 & 1 & 146.7 & 6.96 & 1.232 & 0.01 \\
\hline A2NB82 & Productively rearranged V-lambda-2 & 9.91 & 1 & 12.2 & 6.27 & 1.233 & 0.01 \\
\hline Q62951 & Dihydropyrimidinase-related protein 4 & 2.84 & 1 & 61.0 & 6.77 & 1.237 & 0.00 \\
\hline D3ZHB7 & Protein Ube $3 c$ & 1.57 & 1 & 124.3 & 6.64 & 1.249 & 0.00 \\
\hline Q5U214 & Protein Snrpa & 2.85 & 1 & 31.2 & 9.83 & 1.337 & 0.00 \\
\hline P68136 & Actin & 71.88 & 2 & 42.0 & 5.39 & 1.357 & 0.00 \\
\hline B2RYP0 & Protein Rhoc & 38.34 & 1 & 22.0 & 6.58 & 1.598 & 0.00 \\
\hline P62747 & Rho-related GTP-binding protein RhoB & 20.92 & 1 & 22.1 & 5.24 & 1.666 & 0.00 \\
\hline Q6IFV3 & Keratin & 11.19 & 1 & 48.8 & 4.86 & 2.109 & 0.00 \\
\hline P00684 & Ribonuclease pancreatic beta-type & 15.13 & 2 & 16.8 & 8.29 & 0.589 & 0.00 \\
\hline F1M9X2 & Glycoprotein GP2 & 3.58 & 2 & 58.8 & 5.07 & 0.667 & 0.00 \\
\hline P15865 & Histone H1.4 & 49.32 & 5 & 22.0 & 11.11 & 1.212 & 0.01 \\
\hline A8QIC3 & DnaJ (Hsp40) homolog & 11.97 & 2 & 30.0 & 7.33 & 1.212 & 0.01 \\
\hline F1LSL1 & Transcription factor Pur-beta & 8.52 & 1 & 33.5 & 5.33 & 1.356 & 0.00 \\
\hline M0R6T4 & Protein Mms19l & 2.23 & 1 & 112.9 & 6.24 & 1.784 & 0.00 \\
\hline M0R5F9 & Protein LOC100910864 & 6.38 & 1 & 33.7 & 9.82 & 1.432 & 0.00 \\
\hline P63055 & Purkinje cell protein 4 & 41.94 & 2 & 6.8 & 6.71 & 1.281 & 0.00 \\
\hline Q499T8 & Intelectin 1 & 4.47 & 1 & 34.5 & 5.78 & 1.582 & 0.00 \\
\hline \multicolumn{8}{|l|}{ Diseases } \\
\hline D4A0X4 & Elongation factor 1-alpha & 27.37 & 1 & 48.7 & 8.72 & 0.697 & 0.00 \\
\hline M0RE01 & Uncharacterized protein & 17.65 & 1 & 36.9 & 6.34 & 0.750 & 0.00 \\
\hline Q569A6 & ER lumen protein-retaining receptor 1 & 3.77 & 1 & 24.5 & 8.62 & 0.766 & 0.00 \\
\hline Q4FZS2 & Budding uninhibited by benzimidazoles 3 homolog & 10.74 & 3 & 36.9 & 6.84 & 0.796 & 0.01 \\
\hline D4A5L9 & Protein LOC679794 & 54.29 & 6 & 11.6 & 9.58 & 0.811 & 0.01 \\
\hline Q06645 & ATP synthase $\mathrm{F}(0)$ complex subunit $\mathrm{C} 1$ & 5.15 & 1 & 14.2 & 9.91 & 0.827 & 0.02 \\
\hline D4A817 & Histone $\mathrm{H} 2 \mathrm{~B}$ & 67.46 & 1 & 13.9 & 10.32 & 1.205 & 0.01 \\
\hline Q4QQV6 & Lymphocyte specific 1 & 17.22 & 5 & 36.5 & 4.67 & 1.210 & 0.01 \\
\hline Q9R066 & Coxsackievirus and adenovirus receptor homolog & 6.58 & 1 & 39.9 & 7.27 & 1.214 & 0.01 \\
\hline Q6P725 & Desmin & 73.77 & 27 & 53.4 & 5.27 & 1.229 & 0.01 \\
\hline G3V913 & Heat shock $27 \mathrm{kDa}$ protein 1 & 50.49 & 7 & 22.8 & 6.21 & 1.241 & 0.00 \\
\hline D3ZJ08 & Histone $\mathrm{H} 3$ & 60.29 & 2 & 15.4 & 11.27 & 1.356 & 0.00 \\
\hline Q5FVG5 & Similar to tropomyosin 1 & 69.37 & 10 & 32.9 & 4.67 & 1.279 & 0.00 \\
\hline Q5U1W8 & High-mobility group nucleosome binding domain 1 & 8.33 & 1 & 10.1 & 9.76 & 1.264 & 0.00 \\
\hline Q91XN7 & Tropomyosin alpha isoform & 50.00 & 2 & 28.5 & 4.74 & 1.313 & 0.00 \\
\hline D3ZBP2 & Protein Sin $3 a$ & 2.13 & 1 & 127.7 & 6.61 & 1.458 & 0.00 \\
\hline P49793 & Nuclear pore complex protein Nup98-Nup96 & 0.83 & 1 & 197.2 & 6.23 & 1.761 & 0.00 \\
\hline \multicolumn{8}{|c|}{ Cellular component and process } \\
\hline Q5XI41 & Translocating chain-associated membrane protein 1 & 2.94 & 1 & 43.0 & 9.67 & 0.747 & 0.00 \\
\hline B2RZ37 & Receptor expression-enhancing protein 5 & 13.76 & 2 & 21.4 & 8.12 & 0.743 & 0.00 \\
\hline
\end{tabular}


Table 1 (Contd.)

\begin{tabular}{|c|c|c|c|c|c|c|c|}
\hline Accession & Description & Coverage & Unique peptides & MW $[\mathrm{kDa}]$ & Calc. pI & Fold change & $P$-Value \\
\hline D4AC92 & Sulfotransferase & 9.66 & 2 & 33.5 & 6.95 & 0.751 & 0.00 \\
\hline Q5U3Y7 & Transmembrane protein 97 & 13.07 & 2 & 20.9 & 9.29 & 0.752 & 0.00 \\
\hline D3ZE21 & Protein Tmed11 & 7.94 & 1 & 24.6 & 5.57 & 0.771 & 0.00 \\
\hline Q5U3Z3 & Isochorismatase domain-containing protein 2 & 7.62 & 1 & 23.1 & 7.83 & 0.772 & 0.00 \\
\hline P19944 & $60 \mathrm{~S}$ acidic ribosomal protein $\mathrm{P} 1$ & 14.04 & 1 & 11.5 & 4.32 & 0.786 & 0.00 \\
\hline B5DEQ0 & Translocon-associated protein subunit beta & 3.83 & 1 & 20.0 & 8.35 & 0.792 & 0.01 \\
\hline F1M8X9 & Protein Gbf1 & 0.97 & 1 & 206.4 & 5.80 & 0.797 & 0.01 \\
\hline D3ZPJ2 & Protein RGD1564095 & 10.53 & 1 & 11.6 & 4.64 & 0.801 & 0.01 \\
\hline F1LNE5 & Protein MEMO1 & 6.12 & 1 & 31.6 & 6.95 & 0.803 & 0.01 \\
\hline Q5XIG4 & OCIA domain-containing protein 1 & 7.29 & 1 & 27.6 & 7.42 & 0.813 & 0.01 \\
\hline Q6IG04 & Keratin & 3.65 & 1 & 56.8 & 7.36 & 0.814 & 0.01 \\
\hline P0С5H9 & Mesencephalic astrocyte & 31.84 & 5 & 20.4 & 8.25 & 0.823 & 0.02 \\
\hline D3Z952 & Microfibrillar-associated protein 2 & 5.41 & 1 & 20.8 & 4.89 & 0.824 & 0.02 \\
\hline P62250 & 40S ribosomal protein S16 & 45.21 & 8 & 16.4 & 10.21 & 0.827 & 0.02 \\
\hline P15693 & Intestinal-type alkaline phosphatase 1 & 33.15 & 11 & 58.4 & 6.00 & 0.832 & 0.02 \\
\hline Q9JHW0 & Proteasome subunit beta type- 7 & 3.25 & 1 & 29.9 & 7.97 & 1.204 & 0.01 \\
\hline Q62713 & Neutrophil antibiotic peptide NP-3A & 19.54 & 1 & 9.3 & 7.65 & 1.211 & 0.01 \\
\hline B1WC16 & BCL2-associated transcription factor 1 & 3.47 & 3 & 106.0 & 9.99 & 1.211 & 0.01 \\
\hline F1LLV6 & Protein Ces1f & 5.35 & 1 & 62.4 & 7.12 & 1.215 & 0.01 \\
\hline Q5BJS4 & FUN14 domain-containing protein 1 & 10.97 & 1 & 17.1 & 8.63 & 1.229 & 0.01 \\
\hline Q6AYC8 & $\mathrm{SH} 2$ domain-containing protein $4 \mathrm{~A}$ & 2.84 & 1 & 48.5 & 9.04 & 1.238 & 0.00 \\
\hline MOR4Z0 & Protein Cbx1 & 41.33 & 2 & 17.2 & 5.03 & 1.254 & 0.00 \\
\hline P24051 & 40S ribosomal protein S27-like & 28.57 & 1 & 9.5 & 9.45 & 1.254 & 0.00 \\
\hline Q6IM78 & DNA topoisomerase I & 4.38 & 1 & 69.0 & 9.22 & 1.268 & 0.00 \\
\hline Q6EIX2 & Mitochondrial import inner membrane translocase & 10.48 & 1 & 13.7 & 6.80 & 1.469 & 0.00 \\
\hline D3Z9K7 & Protein Pdia2 & 41.18 & 17 & 58.4 & 4.82 & 0.524 & 0.00 \\
\hline P00773 & Chymotrypsin-like elastase family member 1 & 12.78 & 2 & 29.0 & 8.47 & 0.565 & 0.00 \\
\hline G3V7A3 & Protein Serpini2 & 5.68 & 1 & 45.9 & 6.15 & 0.652 & 0.00 \\
\hline Q5XFW5 & Peptidyl-prolyl cis-trans isomerase & 10.42 & 1 & 10.4 & 4.70 & 0.764 & 0.00 \\
\hline E9PTI2 & Putative lysozyme C-2 & 5.98 & 1 & 13.1 & 6.84 & 1.209 & 0.01 \\
\hline D4A305 & Coiled-coil domain containing 58 & 5.56 & 1 & 16.7 & 8.16 & 0.819 & 0.02 \\
\hline \multicolumn{8}{|c|}{ Oxidative stress } \\
\hline Q5M875 & 17-Beta-hydroxysteroid dehydrogenase 13 & 23.00 & 6 & 33.5 & 9.38 & 0.582 & 0.00 \\
\hline D3ZTP0 & Protein Aldh112 & 2.26 & 1 & 102.9 & 6.39 & 0.618 & 0.00 \\
\hline Q9Z0V5 & Peroxiredoxin-4 & 28.94 & 4 & 31.0 & 6.65 & 0.632 & 0.00 \\
\hline Q6AYT0 & Quinone oxidoreductase & 3.65 & 1 & 35.0 & 8.22 & 0.735 & 0.00 \\
\hline D3ZEN2 & Glyceraldehyde-3-phosphate dehydrogenase & 13.03 & 1 & 35.9 & 8.12 & 0.770 & 0.00 \\
\hline Q5PPL3 & Sterol-4-alpha-carboxylate 3-dehydrogenase & 1.93 & 1 & 40.4 & 8.85 & 0.771 & 0.00 \\
\hline D3Z7Y1 & Uncharacterized protein & 5.47 & 2 & 37.5 & 6.96 & 0.770 & 0.00 \\
\hline Q6AYS8 & Estradiol 17-beta-dehydrogenase 11 & 20.81 & 4 & 32.9 & 8.63 & 0.799 & 0.01 \\
\hline F1M201 & Dehydrogenase/reductase SDR family member 7B & 4.63 & 1 & 35.2 & 9.55 & 0.806 & 0.01 \\
\hline Q5XIB4 & Ufm1-specific protease 2 & 3.25 & 1 & 52.3 & 6.54 & 0.753 & 0.00 \\
\hline \multicolumn{8}{|c|}{ Signaling pathway } \\
\hline Q7TP21 & Cb1-727 & 1.47 & 1 & 75.0 & 8.10 & 1.217 & 0.01 \\
\hline Q6AYK1 & RNA-binding protein with serine-rich domain 1 & 4.92 & 1 & 34.2 & 11.84 & 1.217 & 0.01 \\
\hline G3V9A3 & Protein LOC679816 & 19.76 & 1 & 27.7 & 4.78 & 0.775 & 0.00 \\
\hline Q63450 & Calcium/calmodulin-dependent protein kinase type 1 & 4.81 & 1 & 41.6 & 5.35 & 0.822 & 0.02 \\
\hline Q5XI64 & Monoacylglycerol lipase ABHD6 & 13.95 & 4 & 38.3 & 8.62 & 0.830 & 0.02 \\
\hline Q06486 & Casein kinase I isoform delta & 3.37 & 1 & 47.3 & 9.74 & 1.304 & 0.00 \\
\hline \multicolumn{8}{|c|}{ Enzymatic activity } \\
\hline Q6AYS4 & Plasma alpha-L-fucosidase & 2.40 & 1 & 53.2 & 6.48 & 0.736 & 0.00 \\
\hline D3ZD11 & Protein Spcs2 & 16.37 & 2 & 25.0 & 8.57 & 0.771 & 0.00 \\
\hline D3ZP98 & Histocompatibility 13 & 12.09 & 4 & 40.2 & 6.71 & 0.797 & 0.01 \\
\hline D4A6W4 & Solute carrier family 52 & 2.96 & 1 & 60.3 & 8.59 & 0.798 & 0.01 \\
\hline D3ZL24 & Calpastatin & 6.95 & 3 & 71.7 & 5.08 & 1.244 & 0.00 \\
\hline Q6MG88 & G-Protein-signaling modulator 3 & 11.39 & 1 & 17.5 & 5.85 & 1.257 & 0.00 \\
\hline Q5GAM3 & Ribonuclease 16 & 15.38 & 2 & 17.7 & 9.22 & 1.493 & 0.00 \\
\hline D3Z8M2 & Serine/threonine-protein kinase WNK4 & 2.13 & 2 & 173.0 & 6.33 & 0.762 & 0.00 \\
\hline
\end{tabular}


NCBI BLAST to find homologous sequences for each obtained hit. Functional classification of the identified proteins to the query sequence according to GO resulted in an assessment of the cellular compartments, molecular function, and biological process represented. Enrichment analysis of GO category was conducted using 175 differentially expressed proteins that represent the overall trends of the specific functional categories enriched in intestinal mucosa cells in order to gain more insight into the biological significance of the differentially expressed proteins. Here, 138 proteins (79.77\%) from intestinal mucosa cells with 5079 annotation terms were involved in the GO categories molecular function, biological process, and cellular component (Fig. 4). In the category of molecular function, the majority of differential proteins were found in binding $(45.7 \%)$, catalytic activity $(41.7 \%)$, transporter activity $(3.5 \%)$ and structural molecule activity $(3.5 \%)$ (Fig. 4a). The binding functions included nucleic acid and nucleotide binding, ion binding and protein binding that were mainly at the intracellular level, while catalytic activities included hydrolase and transferase activities. ${ }^{\mathbf{4 4}}$ The category cellular component involved locations, subcellular structures, and macromolecular complexes, such as telomere, nucleus, and origin recognition complex. The differentially abundant proteins in our study were related to cellular components in the intracellular space $(38.7 \%)$, organelle $(26.9 \%)$, membrane (12.5\%), macromolecular complex (11.8\%) and extracellular region (5.4\%) (Fig. 4b). The final category, biological process included broad biological goals, such as purine metabolism or mitosis. The majority of proteins in our study were found in cellular process $(17.4 \%)$, metabolic process $(16.1 \%)$, single organism process $(15.6 \%)$, response to stimulus $(10.2 \%)$, biological regulation (9.8\%) and multicellular organismal process (8.5\%) (Fig. 4c). The functional annotation will help us to effectively analyze the differentially expressed unigenes caused by Mn exposure.

\subsection{KEGG automatic annotation server (KAAS)}

KEGG pathway enrichment can reveal protein functional information in the metabolic pathway through analyzing the differentially expressed proteins. ${ }^{45}$ The KEGG pathway is a collection of manually drawn pathway maps graphically displaying the distribution of differentially expressed genes among the biochemical pathways. In our study, intestinal mucosa proteins in Mn-treated rats were annotated to biochemical pathways from the KO number of the homologous/similar proteins through aligning with rat protein sequences in the KEGG GENES database using KAAS. The signal/metabolic pathway associations for 93 differential proteins with 140 unique KEGG orthologues were established. The most represented KEGG maps were protein processing in pancreatic secretion (15 members, path: ko04792), bile secretion (2 members, path: ko04976); protein digestion and absorption (10 members, path: ko04974), fat digestion and absorption (7 members, path: ko04975), biosynthesis of amino acids (6 members, path: ko01230), glycerolipid metabolism (5 members, path: ko00561), glycine, serine and threonine metabolism (5 members, path: ko00260), arginine and proline metabolism (3 members, path: ko00330), cysteine and methionine metabolism (3 members, path: ko00270), carbohydrate digestion and absorption (3 members, path: ko04973); Huntington's disease (4 members, path: ko05016), Alzheimer's disease (3 members, path: ko05010), Parkinson's disease (2 members, path: ko05012), etc. (Fig. 5). Upon Mn exposure, profound metabolic changes and activation/deactivation occur in a vast number of intracellular pathways.

$\mathrm{Mn}^{2+}$ is taken up by glucose-activated $\beta$-cells, resulting in a robust signal increase in glucose-stimulated rodent $\beta$-cell lines and in islets. ${ }^{46} \mathrm{Mn}^{2+}$ can be used to characterize isolated islet potency in vitro and assess the functionality of both grafted and endogenous pancreatic islets in vivo. ${ }^{47} \mathrm{Mn}^{2+}$ is excreted from blood into bile to form complexes with bile acids. ${ }^{28}$ Our results showed that high concentrations of $\mathrm{Mn}^{2+}$ disturbed the secretion of pancreas and bile, which is consistent with the above theories. Mineral metabolism can interact with the metabolism of macronutrients such as proteins and fats. ${ }^{48}$ Our study also demonstrated that Mn exposure is associated with significantly perturbed amino acid metabolism, fatty acid metabolism and carbohydrate metabolism. These results are consistent with our previous finding that Mn exposure significantly altered the concentrations of 36 metabolites in the plasma of rats, which were associated with amino acid metabolism and fatty acid metabolism. ${ }^{11}$ Exposure to high Mn levels causes neurodegenerative diseases including Parkinson's disease, Huntington's disease and Alzheimer's disease, ${ }^{\mathbf{4 9}}$ caused by $\mathrm{Mn}$ preferentially accumulating in the globus pallidus, striatum, substantia nigra and subthalamic nucleus. ${ }^{50}$ The results observed in this study were consistent with these important findings.

\subsection{Protein-protein interaction analysis}

The elementary part of protein complexes is protein function in living cells. However, protein function does not act independently. In addition to KEGG, the protein-protein interactions (PPI) network was also constructed using STRING Database version 10.5. Fig. 6 shows the results that were in accordance with the Pathway and GO analysis highlighting different groups of PPI; 16 proteins have various relationships in PPI and were recognized as key nodes: anionic trypsin-1 (Prss1), chymotrypsin-like elastase family member 2A (Cela2a), chymotrypsin-like protease CTRL-1 precursor (Ctrl), chymotrypsin-like elastase family member 3B precursor (Cela3b), glyceraldehyde-3-phosphate dehydrogenase (Gapdh), peroxiredoxin-4 (Prdx4), chymotrypsin-like elastase family member 1 (Cela1), Rho-related GTP-binding protein RhoB (Rhob), carboxypeptidase A1 (Cpa1), electron carrier protein (LOC690675), histone H3 (Hist2h3c2), GDH/ 6PGL endoplasmic bifunctional protein precursor (H6pb), calcium/calmodulin-dependent protein kinase type 1 (Camk1), protein LOC298795 (Sfn), actin (Acta1) and solute carrier family 2 (Slc2a5). A number of proteins were associated with pancreatic secretion, protein digestion and absorption: Cela2a, Cela3b, Cpa1, Ctrl, Pnlip, Prss1, Try4; 
(a)

\section{Molecular Function}

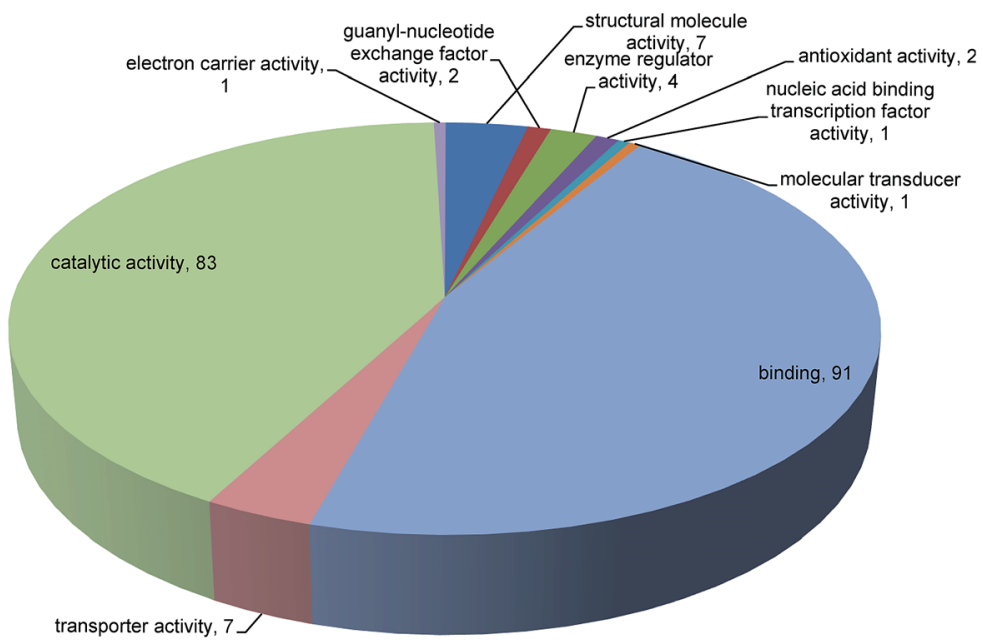

(b)

\section{Cellular Component}

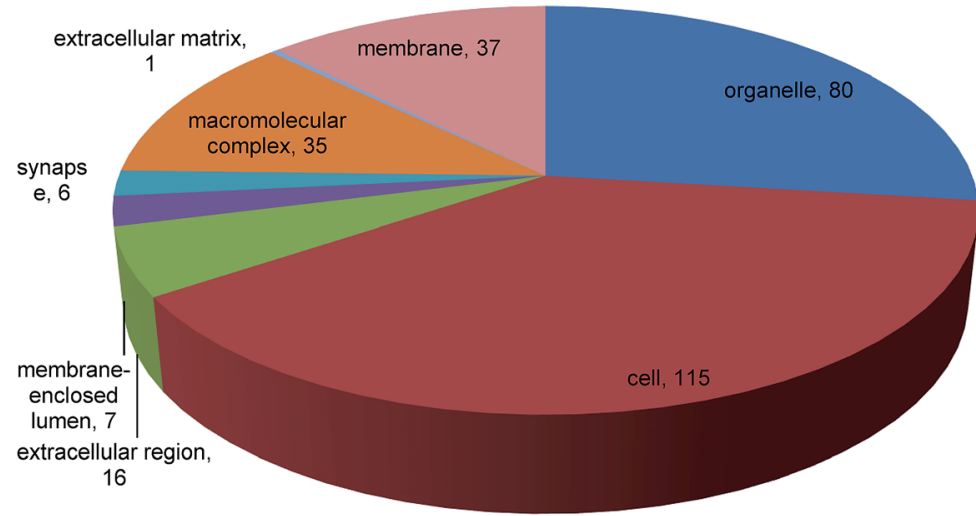

(c)

\section{Biological Process}

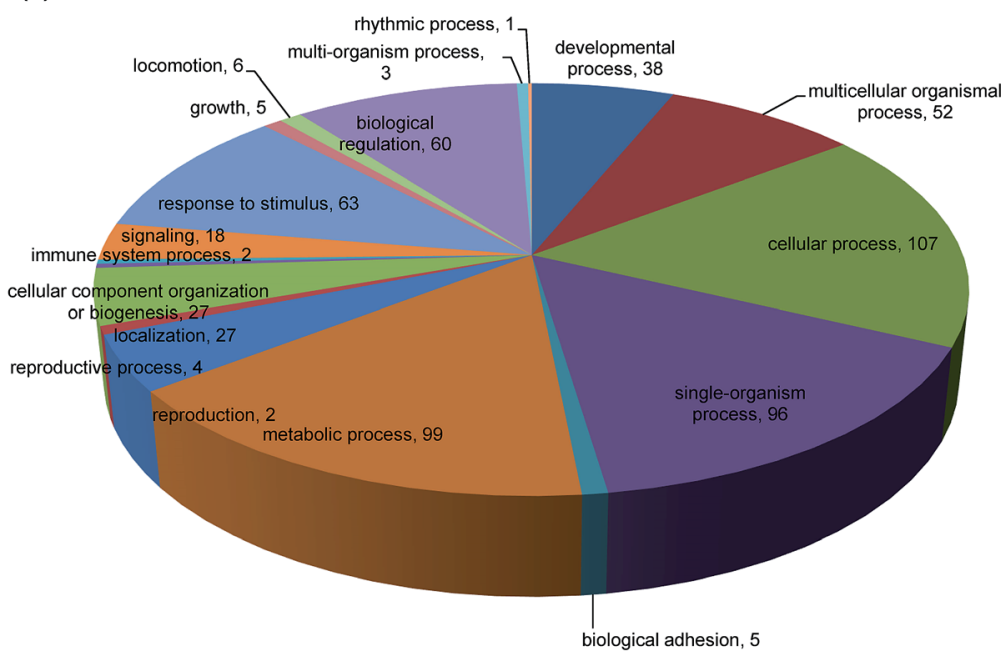

Fig. 4 Distribution of GO terms in the categories molecular function (a), cellular component (b), and biological process (c). In (a), binding and catalytic activity were the most represented biological processes. In (b), the most represented categories were cell, followed by organelle. In (c), the most represented categories were metabolic process and cellular process. 
(a)
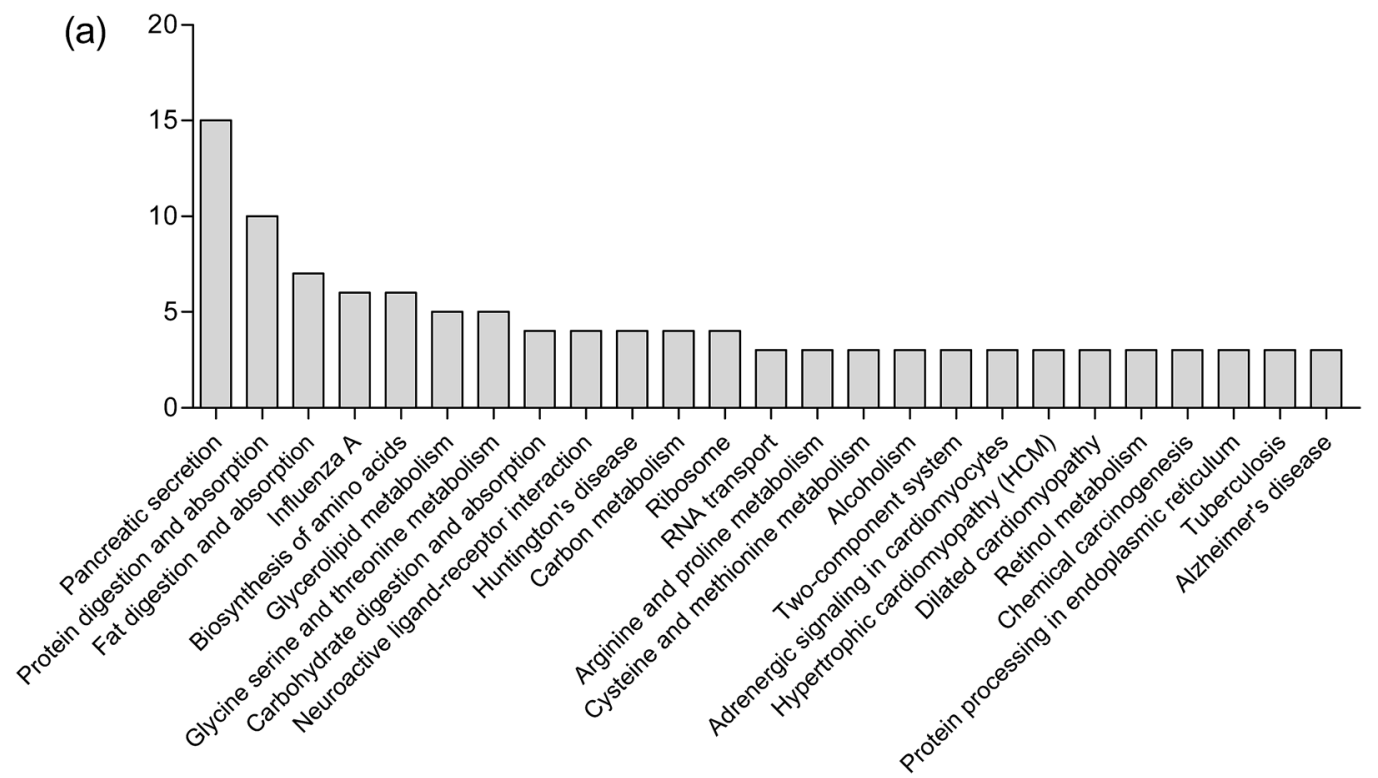

(b)
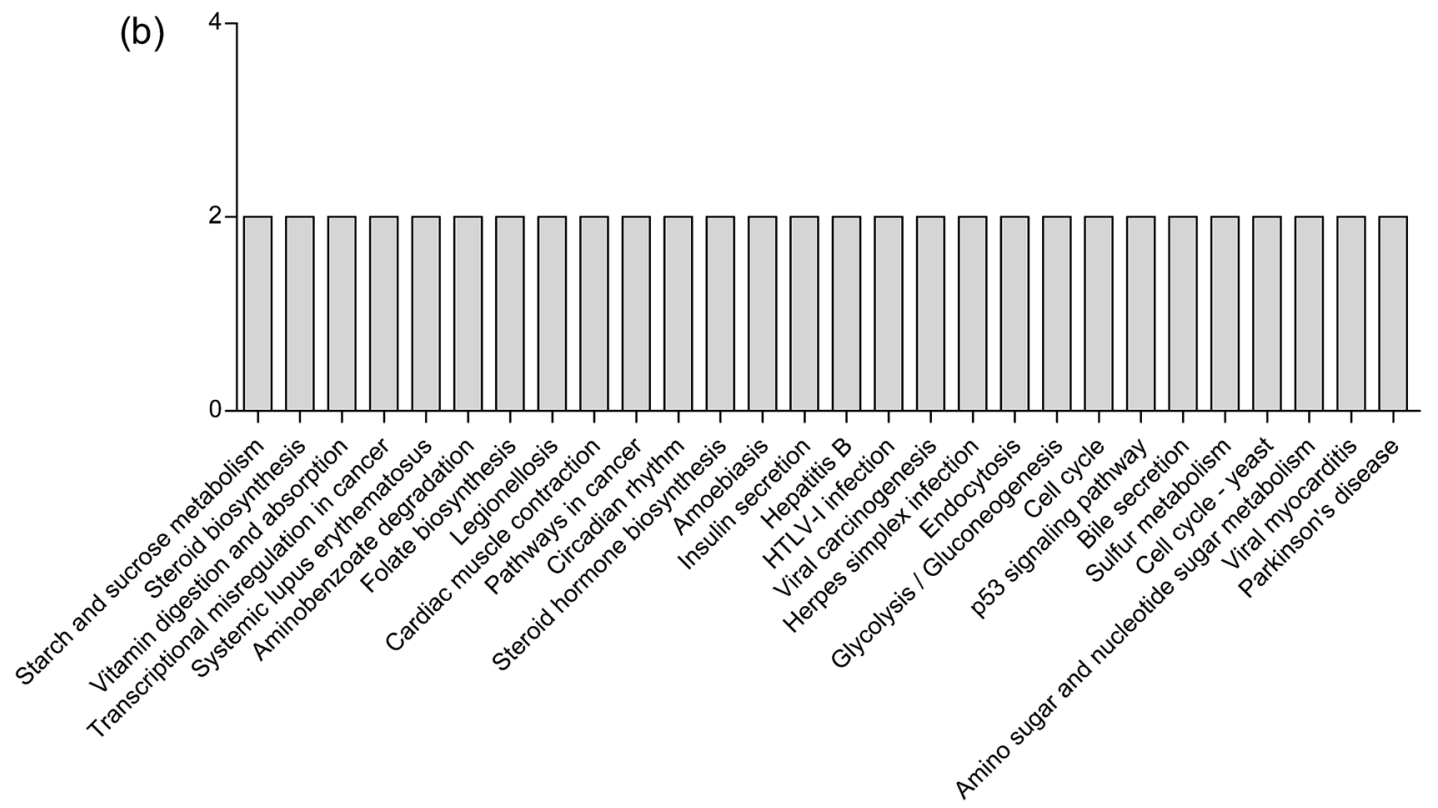

Fig. 5 The most represented KEGG maps ( $a$ and b).

with metabolic pathways: Alpi, Asah2, Asns, Atp5g1, Cpox, Cth, Ctps, Gatm, Gmppb, H6pd, LOC690675, Mri1, Nsdhl, Pc, Pnlip, Psat1, Pycr1, Tst; with proteasome: psma1, psma2, psma3, psma4, psmb7; and with structural molecule activity: Rplp1, Rps27l, RGD1564095, Rps3a, Rps11, Rps15, Rps16, Csnk1d; which were differentially expressed through $\mathrm{Mn}$ exposure. $\mathrm{Mn}$ is a cofactor in numerous enzymatic processes, so it is essential for brain biology and physiology. But excessive levels of $\mathrm{Mn}$ in two neurodegenerative syndromes (Huntington and Parkinson's disease) result in neuronal loss in the basal ganglia, ${ }^{51,52}$ pathological changes in the striatum, ${ }^{53}$ as well as having effects on mitochondrial dysfunction and disruption of cellular energy metabolism. ${ }^{7,54}$ Specifically, we found that four proteins were involved in Huntington's disease, Alzheimer's disease and Parkinson's disease: Gapdh, Atp5g1, OC690675, and Creb1. S100 proteins are calciumbinding proteins that are involved in controlling diverse extracellular and intracellular processes such as differentiation, cell growth, and antimicrobial function. ${ }^{55,56} \mathrm{~S} 100$ protein family members exhibit variable affinities for oligomerization properties, post-translational modifications, divalent metal ions, and unique spatial/temporal expression patterns. ${ }^{57}$ In our study, the mineral absorption associated protein (S100G) was also differentially expressed. Results of the current study indicated that Mn exposure altered the small intestinal proteomes in rats. 


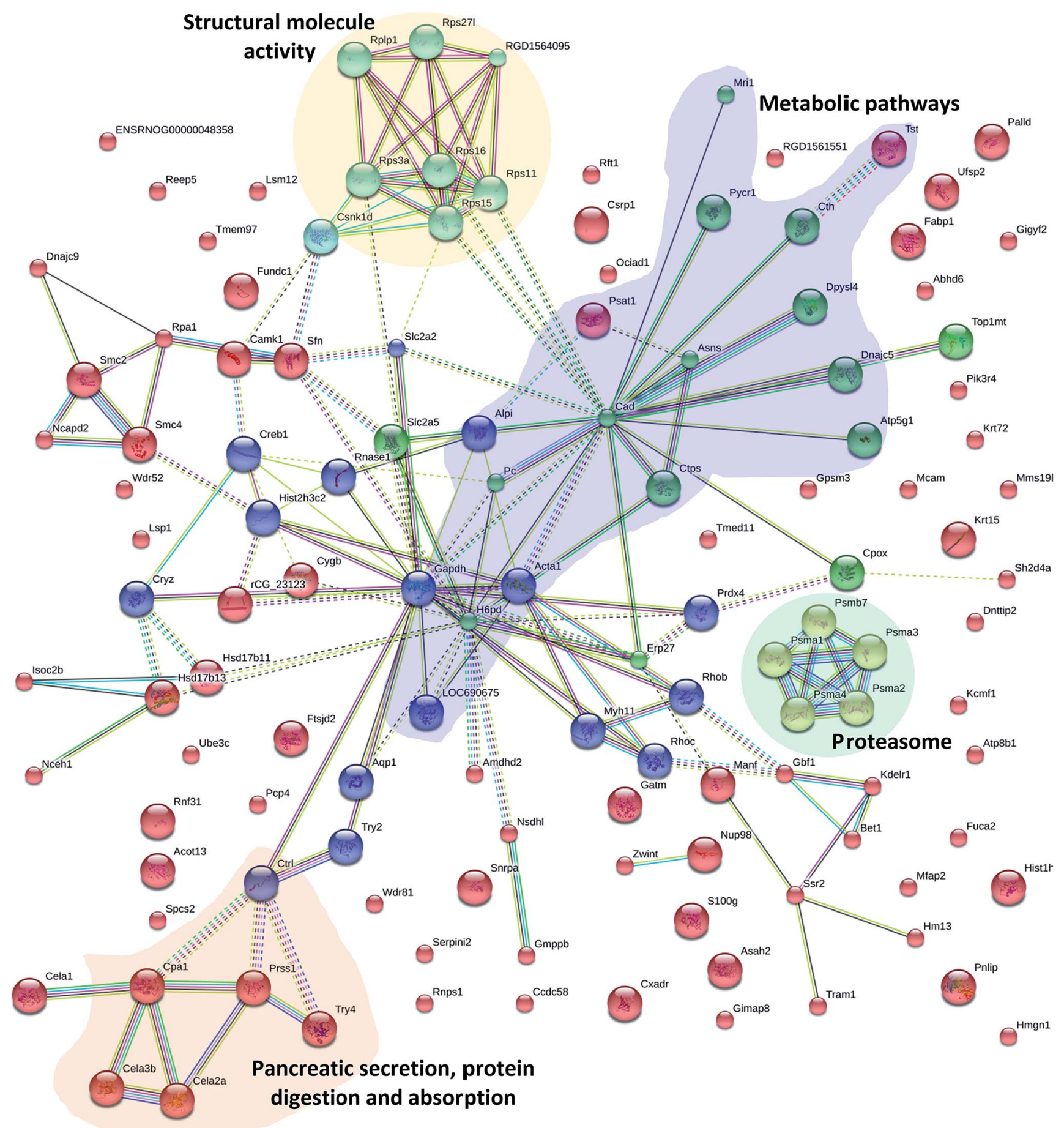

Fig. 6 Protein-protein interaction analysis of cluster 4 highlighting protein networks involved in pancreatic secretion, protein digestion and absorption (orange), metabolic pathways (purple), proteasome (green) and structural molecule activity (yellow). In the network, proteins are represented as nodes. Colors of the lines connecting the nodes represent different evidence types for protein linkage.

\section{Conclusions}

All organisms require mechanisms for sensing small fluctuations to maintain a controlled balance of efflux, uptake, and sequestration in metal levels and to ensure that metal availability is physiologically controlled. ${ }^{2}$ In conclusion, chronic exposure to a high concentration of Mn significantly changed the behavioral patterns in the rat producing motor disturbances and altering the protein expression profile in rats' intestinal mucosa cells. A total of 175 intestinal mucosa proteins that may regulate Mn levels were identified using iTRAQ-based proteomic technology under biologically relevant Mn exposures. These proteins are involved in pancreatic secretion, protein digestion and absorption, fat digestion and absorption, biosynthesis of 
amino acids, Alzheimer's and Parkinson's disease, etc. The targets of these proteins related to Mn exposure may improve our understanding of the regulation of $\mathrm{Mn}$ homeostasis and intracellular and cellular Mn trafficking.

\section{Conflict of interest}

The authors declare no competing financial interest.

\section{Acknowledgements}

Financial support from the Gansu Provincial Natural Science Foundation (No. 1606RJYA224), the National Key Research and Development Plan (No. 2016YFD0501200) and the Central Public-interest Scientific Institution Basal Research Fund (No. 1610322013003) is greatly appreciated. We would also like to thank Shanghai Applied Protein Technology Co. Ltd for their technical assistance.

\section{Notes and references}

1 Z. Ma, F. E. Jacobsen and D. P. Giedroc, Chem. Rev., 2009, 109, 4644-4681.

2 M. I. Hood and E. P. Skaar, Nat. Rev. Microbiol., 2012, 10, 525-537.

3 S. Tottey, K. J. Waldron, S. J. Firbank, B. Reale, C. Bessant, K. Sato, T. R. Cheek, J. Gray, M. J. Banfield, C. Dennison and N. J. Robinson, Nature, 2008, 455, 1138-1142.

4 K. J. Waldron and N. J. Robinson, Nat. Rev. Microbiol., 2009, 7, 25-35.

5 D. P. Giedroc and A. I. Arunkumar, Dalton Trans., 2007, 29, 3107-3120.

6 D. W. Domaille, E. L. Que and C. J. Chang, Nat. Chem. Biol., 2008, 4, 168-175.

7 K. J. Horning, S. W. Caito, K. G. Tipps, A. B. Bowman and M. Aschner, Annu. Rev. Nutr., 2015, 35, 71-108.

8 B. Michalke, J. Trace Elem. Med. Biol., 2016, 31, 50-61.

9 D. L. Stredrick, A. H. Stokes, T. J. Worst, W. M. Freeman, E. A. Johnson, L. H. Lash, M. Aschner and K. E. Vrana, Neurotoxicology, 2004, 25, 543-553.

10 A. Takeda, Brain Res. Rev., 2003, 41, 79-87.

11 H. Wang, Z. Liu, S. Wang, D. Cui, X. Zhang, Y. Liu and Y. Zhang, Metallomics, 2017, 9, 192-203.

12 S. C. Pearce, S. M. Lonergan, E. Huff-Lonergan, L. H. Baumgard and N. K. Gabler, PLoS One, 2015, 10, e0143099.

13 K. K. Kumar, E. W. Lowe Jr, A. A. Aboud, M. D. Neely, R. Redha, J. A. Bauer, M. Odak, C. D. Weaver, J. Meiler, M. Aschner and A. B. Bowman, Sci. Rep., 2014, 4, 6801.

14 A. Nel, T. Xia, H. Meng, X. Wang, S. Lin, Z. Ji and H. Zhang, Acc. Chem. Res., 2012, 46, 607-621.

15 L. Su, L. Cao, R. Zhou, Z. Jiang, K. Xiao, W. Kong, H. Wang, J. Deng, B. Wen, F. Tan, Y. Zhang and L. Xie, PLoS One, 2013, 8, e54237.

16 A. Glen, C. A. Evans, C. S. Gan, S. S. Cross, F. C. Hamdy, J. Gibbins, J. Lippitt, C. L. Eaton, J. Noirel, P. C. Wright and I. Rehman, Prostate, 2010, 70, 1313-1332.
17 J. H. Zhang, Y. Li, X. B. Song, X. H. Ji, H. N. Sun, H. Wang, S. B. Fu, L. J. Zhao and D. J. Sun, Toxicol. Res., 2016, 5, 651-659.

18 T. Monsinjon and T. Knigge, Proteomics, 2007, 7, 2997-3009. 19 M. F. Lemos, A. M. Soares, A. C. Correia and A. C. Esteves, Proteomics, 2010, 10, 873-887.

20 E. F. Petricoin, A. M. Ardekani, B. A. Hitt, P. J. Levine, V. A. Fusaro, S. M. Steinberg, G. B. Mills, C. Simone, D. A. Fishman, E. C. Kohn and L. A. Liotta, Lancet, 2002, 359, 572-577.

21 P. G. Reeves, F. H. Nielsen and G. C. Fahey, J. Nutr., 1993, 123, 1939-1951.

22 WHO, Guidelines for drinking-water quality, Health criteria and other supporting information, World Health Organization, Geneva, 2nd edn, 1996, vol. 2.

23 X. Wang, S. Qiao, Y. Yin, L. Yue, Z. Wang and G. Wu, J. Nutr., 2007, 137, 1442-1446.

24 H. Wang, Z. Liu, M. Huang, S. Wang, D. Cui, S. Dong, S. Li, Z. Qi and Y. Liu, Biol. Trace Elem. Res., 2016, 172, 326-335.

25 J. R. Wiśniewski, A. Zougman, N. Nagaraj and M. Mann, Nat. Methods, 2009, 6, 359-362.

26 A. Sandberg, G. Lindell, B. N. Källström, R. M. Branca, K. G. Danielsson, M. Dahlberg, B. Larson, J. Forshed and J. Lehtiö, Mol. Cell. Proteomics, 2012, 11, M112.016998.

27 E. Choleris, A. W. Thomas, M. Kavaliers and F. S. Prato, Neurosci. Biobehav. Rev., 2001, 25, 235-260.

28 Q. Ye, J. E. Park, K. Gugnani, S. Betharia, A. Pino-Figueroa and J. Kim, Metallomics, 2017, DOI: 10.1039/c7mt00079k.

29 A. Uchino, T. Noguchi, K. Nomiyama, Y. Takase, T. Nakazono, J. Nojiri and S. Kudo, Neuroradiology, 2007, 49, 715-720.

30 J. R. Wiśniewski, A. Friedrich, T. Keller, M. Mann and H. Koepsell, J. Proteome Res., 2014, 14, 353-365.

$31 \mathrm{H}$. M. Zeron, M. R. Rodriguez, S. Montes and C. R. Castaneda, J. Trace Elem. Med. Biol., 2011, 25, 225-229.

32 L. S. Kaminsky and Q. Y. Zhang, Drug Metab. Dispos., 2003, 31, 1520-1525.

33 T. Nilsson, M. Mann, R. Aebersold, J. R. Yates, A. Bairoch and J. J. Bergeron, Nat. Methods, 2010, 7, 681-685.

34 J. Storch and L. McDermott, J. Lipid Res., 2009, 50, S126S131.

35 J. Wang, Y. Y. Wang, L. Lin, Y. Gao, H. S. Hong and D. Z. Wang, J. Proteomics, 2012, 75, 2038-2052.

36 T. Jursa and D. R. Smith, Toxicol. Sci., 2009, 107, 182-193.

37 K. A. Brenneman, R. C. Cattley, S. F. Ali and D. C. Dorman, Neurotoxicology, 1999, 20, 477-487.

38 X. M. Shen and G. Dryhurst, Chem. Res. Toxicol., 1998, 11, 824-837.

39 A. W. Dobson, K. M. Erikson and M. Aschner, Ann. N. Y. Acad. Sci., 2004, 1012, 115-128.

40 D. HaMai and S. C. Bondy, Ann. N. Y. Acad. Sci., 2004, 1012, 129-141.

41 A. K. Chandra, R. Ghosh, A. Chatterjee and M. Sarkar, J. Inorg. Biochem., 2007, 101, 944-956.

42 F. Di Domenico, R. Sultana, G. F. Tiu, N. N. Scheff, M. Perluigi, C. Cini and D. A. Butterfield, Brain Res., 2010, 1333, 72-81. 
43 D. W. Huang, B. T. Sherman and R. A. Lempicki, Nucleic Acids Res., 2009, 37, 1-13.

44 M. Lechpammer, M. S. Clegg, Z. Muzar, P. A. Huebner, L. W. Jin and S. M. Gospe Jr, Ann. Neurol., 2014, 75, 608-612.

45 A. Franceschini, D. Szklarczyk, S. Frankild, M. Kuhn, M. Simonovic, A. Roth, J. Lin, P. Minguez, P. Bork, C. von Mering and L. J. Jensen, Nucleic Acids Res., 2013, 41, D808D815.

46 M. Nagata, T. Kagawa, D. Koutou, T. Matsushita, Y. Yamazaki and K. Murase, Radiological Physics and Technology, 2011, 4, 7-12.

47 A. Meyer, K. Stolz, W. Dreher, J. Bergemann, V. H. Thimmashetty, N. Lueschen, Z. Azizi, V. Khobragade, K. Maedle and E. Kuestermann, Diabetes, 2015, 64, 21382147.

48 J. J. Cao and F. H. Nielsen, Curr. Opin. Clin. Nutr. Metab. Care, 2010, 13, 698-702.
49 A. B. Bowman, G. F. Kwakye, E. H. Hernandez and M. Aschner, J. Trace Elem. Med. Biol., 2011, 25, 191-203.

50 C. W. Olanow, Ann. N. Y. Acad. Sci., 2004, 1012, 209-223.

51 Q. Yu, Y. Xiong, H. Gao, J. Liu, Z. Chen, Q. Wang and D. Wen, Virol. J., 2015, 12, 115.

52 B. B. Williams, G. F. Kwakye, M. Wegrzynowicz, D. Li, M. Aschner, K. M. Erikson and A. B. Bowman, Toxicol. Sci., 2010, 117, 169-179.

53 J. L. Madison, M. Wegrzynowicz, M. Aschner and A. B. Bowman, PLoS One, 2012, 7, e31024.

54 M. Aschner, K. M. Erikson, E. Herrero Hernández and R. Tjalkens, NeuroMol. Med., 2009, 11, 252-266.

55 R. Donato, B. R. Cannon, G. Sorci, F. Riuzzi, K. Hsu, D. J. Weber and C. L. Geczy, Curr. Mol. Med., 2013, 13, 24-57. 56 J. H. Kwek, A. Wynne, C. Lefèvre, M. Familari, K. R. Nicholas and J. A. Sharp, Mol. Phylogenet. Evol., 2013, 69, 4-16.

57 D. B. Zimmer, J. O. Eubanks, D. Ramakrishnan and M. F. Criscitiello, Cell Calcium, 2013, 53, 170-179. 